workload studies: one is a national study presenting an overview, and the other a description of the effect of changes in the population within one practice.

Balarajan and colleagues at the University of Surrey, using data from the general household surveys, analysed contacts with general practitioners (at the surgery, at home, and by telephone) of 64000 people (p 953). Even in this large population the numbers for each ethnic group were small when compared with the indigenous white population. Comparison of consultation rates for children showed small differences among Indian, West Indian, and white groups, but Pakistani boys had a consultation rate $44 \%$ higher than white boys and 60\% higher than Pakistani girls. Pakistani men consulted twice as often as white men, and Indian and West Indian men had slightly higher consultation rates than white men. Pakistani and Indian women consulted more often than white or West Indian women, who had similar consultation patterns. When adjustment was made for age and socioeconomic factors the levels of consultation by adults of both sexes for the three ethnic groups were raised, with Pakistani men having a rate three times that of white men and Pakistani women twice that of white women.

Gillam and colleagues looked at the effect such differences had on an inner city London practice and offered some explanations. Their senior partner had witnessed the proportion of patients of British descent go from $90 \%$ to $35 \%$ in 35 years; the current makeup includes $22 \%$ West Indian, $16 \%$ Irish, and $10 \%$ Asian. By comparing the total number of attendances for each ethnic group per disease group and the number of people consulting per person at risk by ethnic group they were able to analyse both the incidence of diseases and frequency of consultations. The Irish and West Indian populations consulted less often than the British; the Asians consulted more often because patients who consulted did so more frequently. Within specific disease groups Gillam and colleagues could define higher levels for endocrine disease, especially diabetes for West Indian women and Asian men, and increased consultations for West Indians and Asian men for diseases of the circulatory system. Asian men consulted more frequently for upper respiratory tract infections, and all non-British ethnic groups consulted less frequently for mental disorders. Patients of British descent were more likely to leave with a follow up appointment, indicating a different doctor-patient conception of the consultation.

The authors of both papers acknowledge the difficulties of their analyses, but their conclusions are important for British general practice. Ethnic differences in disease rates have been reported from mortality statistics and hospital surveys. ${ }^{6-12}$ Specific diseases such as diabetes, hypertension, ischaemic heart disease, and asthma are known to have higher incidences in the West Indian and Asian communities, ${ }^{811}$ as are less common diseases such as rickets, tuberculosis, and race specific anaemias. ${ }^{i 110}$ Ethnic variations in psychiatric illness have also been clearly shown. ${ }^{1213}$

The contributions of heredity and environmental and cultural factors to these differences have still to be worked out in detail. The higher level of cardiovascular disease without an association with the known risk factors of smoking, obesity, and high serum lipid concentrations seems to be one example of genetic variation." The change in the incidence of asthma in first and second generation Afro-Caribbean families" and the differing levels of cancer in immigrants to this and other countries when compared with both their home and adoptive country indicate environmental factors. ${ }^{1+15}$ Ethnic groups often live in inner cities with associated poor housing, overcrowding, unemployment, and other factors of socioeconomic deprivation: all these are known to lead to a higher incidence of ill health. ${ }^{516}$
The higher frequency of consultations in non-British ethnic groups may also be explained partly by cultural factors and attitudes to the sick role-cultural differences affect physician and patient alike in Britain, where doctors come from many ethnic groups. ${ }^{17} 18$ These differences may lead to variations in doctor-patient interactions and differing attitudes to disease, illness, sick role, treatment, and death. ${ }^{17}$

The changes that are planned for the National Health Service and general practice will need to take account of the messages in these papers. Differences in consultation rates are not considered in the new general practitioner contract, and if the care of diabetes, hypertension, and other chronic diseases is to move into the community then general practitioners who care for ethnic groups with higher incidences of these diseases and differing perceptions of medical care will require greater support - and bigger budgets.

General Practitioner,

TIM CARNEY

Hexham,

Northumberland NE46 2ED

1 Carney TA. Workload of general practitioners. Br. Med f 1989:299:753-4.

Rakson SW. An urban group practice in a mainly Asian community. Cpdate 1982:30:617-28.

Pinsent R. Morbidity in an immigrant population. Lancet 1963;i:437-8.

Carne S. Immigrant patient and general practitioner. Procedings of the Reval Soctety of Medicine 1970:63:629-31.

Johnson MRD, Cross M, Cardew SA. Inner city residents, ethnic minorities and primary health care. Pestgrad Med f 1983:59:664-7.

6 Balarajan R. Bulusu L, Adelstein AM, Shilkla V. Patterns of mortality among migrants to England and Wales from the Indian subcontinent. Br. 11ed f 1984:829:1185-7.

Oonaldson LJ, Tavlor JB. Patterns of Asian and non-Asian morbidity in hospital. Br Med $\mathrm{F}$ 1983:286:949-51

8 Cruickshank JK, Beevers D(; () (shourne VL. Haynes RA, Corlen JCR, Selhy S. Heart attack, stroke, diabetes, and hypertension in West Indians, Asians, and whites in Birmingham, England. Br.Mid f 1980;281:1108.

9 Freedman DB. Metabolic disorders in the Asian community. Update 1988:36:1990-4

10 Black JA. Paediatric problems in the Asian community. Update 1987:35:1300-9.

11 Anonvmous. Ethnic factors in disease [Editorial]. Br Med $71981 ; 282: 1496-7$.

12 Qureshi B. Discase patterns in multi-cthnic groups in the UK. I R Soc Health 1985; 104:153-5.

13 Cochrane R, Roc MS. Psychological symptom levels in Indian immigrants to England-a comparison with native English. Psychol Med 1981:11:319-27.

1+ Adelstein AM, Staszewski J, Muir CS. Cancer mortality in 1970-72 among Polish born immigrants to England and Wales. Br f Cancer 1979;40:464-75.

15 Newman AM, Spengler RF. Cancer mortality among immigrant populations in Ontario 1969 thru 1973. Can Med Assoc f 1984:130:339-405.

16 Black D, Morris JN, Smith C, Townsend P. Inequalities in health (the Black report). Harmondsworth: Penguin, 1982.

17 Payer L. Medicine and culture'. New York: Henry Holt, 1989.

18 Fry J, Brooks D, McColl I. NHS datu hook. Lancaster: MTP Press, 1984.

\section{Control of Substances Hazardous to Health}

\section{New legislation with implications for the NHS}

On 1 October new laws on health and safety came into force in Britain. The control of Substances Hazardous to Health regulations ${ }^{1}$ are probably the most important piece of legislation for occupational health since the Health and Safety at Work Act 1974. ${ }^{2}$ They will have far-reaching implications for all workplaces where substances hazardous to health are used, ranging from industrial to health services sites. Many chemicals used in the health service will fall into the definition of a substance hazardous to health, and micro-organisms have also been included. Any risks to patients from drugs given as medical treatment do not, however, come within the scope of these regulations, though risks to staff carrying out such treatment are included.

Some of these new regulations will require immediate action in hospitals and even in general practitioners' premises. Regulation 6 requires that "an employer shall not carry on any work which is liable to expose any employees to any substance hazardous to health unless he has made a suitable and sufficient assessment of the risks ... and of the steps that need 
to be taken. ..." Regulation 12 requires employers to provide information, instruction, and training to employees so that they understand the risks to health posed by these substances and the correct precautions needed. Other sections require keeping records of environmental monitoring and health surveillance and the examination and testing of respiratory protective equipment and local exhaust ventilation at specified intervals.

The responsibility for ensuring compliance with the regulations lies primarily with the employer, who may delegate all or part to one or more competent persons. In the health service this might be a departmental supervisor or manager, the head of a laboratory or clinical department or ward, a safety officer, or occupational health staff. The Health and Safety Executive has produced several approved codes of practice and supporting documents to help such staff understand and comply with the regulations. The suggested strategy for health authorities starts with appointing a coordinator and setting up a "control of hazardous substances team." Authority has to be delegated to competent people and resource implications have to be considered and provisions made for adequate equipment, authority, and support. An early essential step will be preparing an inventory of substances used in each department, with information on how much is used, how often, by how many people, and for which procedures. One benefit of this exercise is that it may identify obsolete substances, which can be discarded.

Priority must be given to protection against health hazards to health care staff that have already been documented. Examples are exposure to glutaraldehyde in endoscopy units, ${ }^{3}$ mercury in the repair of sphygmomanometers, ${ }^{+}$anaesthetic agents, ${ }^{5}$ and cytotoxic drugs. ${ }^{6}$ Procedures for protection against tuberculosis, hepatitis $\mathrm{B}$, and other infections need to be reviewed. Provision may need to be made for measurement of exposure. Two Scottish health boards already have industrial hygienists as members of their occupationar health departments, but we have yet to see the first industrial hygienist employed by the NHS in England and Wales.

The Department of Health has commissioned the University of Birmingham's Institute of Occupational Health to produce a form to be used in the initial assessment of health service premises under the Control of Substances Hazardous to Health regulations. The institute has asked doctors in the Association of NHS Occupational Physicians (ANHOPS) and occupational health nurses to help in this task; it plans a standardised approach to assessment to ensure uniformity and help in any later evaluations and comparisons. Once completed and documented, each assessment should need no further work unless there is a change in procedures or in exposure-or some new knowledge calls for changes.

If all this seems to be rather rushed, there are several justifications for urgency within the NHS. These include the removal of crown immunity for the health service, the increasing interest and familiarity of health and safety inspectors with health service premises, and adverse publicity about poor hygiene and safety in the NHS with closure of some hospital kitchens and outbreaks of legionnaires' disease. Health service administrators, managers, and heads of departments will need to make an early start in understanding and implementing the Control of Substances Hazardous to Health regulations. The prime purpose of the regulations, after all, is the protection of their staff and themselves against chemical and microbiological hazards in their workplace.

TAR-CHING AW

Senior Lecturer in Occupational Medicine,

Institute of Occupational Health,

University of Birmingham,

Birmingham B15 2TT
1 Control of Substances Hazardous to Health Regulations 1988. London: HMSO, 1988. (Statutors Instruments 1988 No 1657

Health and Safety at Work Ace 1974. London: HMSO, 1975

Burge PS. Occupational risks of glutaraldehyde. Br Med 7 1989;299:3+2.

Ide CW. Mercury hazards arising from the repair of sphygmomanometers. Br.Med 7 1986;293:1409. Harrington JM. The health of anaesthetists. Anaesthesia 1987;42:131-2.

6 Vainio $H$. Inhalation anesthesia, anticancer drugs and sterilants as chemical hazards in hospitals Siand f W'ork Eineirom Health 1982:8:94-107.

\section{The NHS boot}

\section{Computers could transform provision}

Of all the appliances and devices available through the NHS, surgical footwear is the greatest cause of dissatisfaction among patients and prescribers. The Department of Health and Social Security published an extensive study of patient satisfaction with NHS footwear in 1979 based on 1500 patients. ${ }^{1}$ The minister at the time was happy to report that the study showed that there was a "high level of satisfaction" $-82 \%$ of patients said that they were satisfied with their footwear. Closer examination of the results showed that the $82 \%$ was derived from the numbers who did not complain. In fact a further $9 \%$ were stated as having felt like complaining, but they had not done so. Put another way, more than one in four patients had a complaint. More recent studies have drawn attention to widespread deficiencies, ${ }^{23}$ and the most recent Department of Health study clearly singled out "footwear" as the most troublesome product."

Patients often find their boots and shoes ugly and uncomfortable and that they do not last long enough. Clearly there is substantial wastage due to little or no use of shoes supplied. A study from Nottingham discloses that almost a fifth of shoes were abandoned after three years ( $p$ 950). In many cases the reason was difficulty in using them. The authors recommend more extensive use of "modular" deep shoes, which are better looking, cost much less, and may have easier fastenings. Wider use of this form of footwear was advocated by Klenerman and Hughes.+ They are not, however, the answer to all footwear problems: the "surgical" shoe made to measure still has a place for patients with more severely disordered feet.

Doctors prescribing modular shoes have to be very sure of their ground. They should be able to turn to the orthotist to obtain a dispassionate view of what is best. Unfortunately, with the current contract most orthotists are employed by the companies who supply the orthoses, and they must have some degree of interest in company turnover. They would be free of these pressures if the contract separated the goods from the fitter, as is the case in the few hospitals that employ their own orthotists.

The earlier studies of consumers' views found that delays in delivery of footwear were a major source of dissatisfaction. ${ }^{12}$ New data from 821 prescribers of footwear obtained by Lord and Foulston showed that the single most apparent need was for improved speed of delivery. ${ }^{5}$ This research was part of a larger feasibility study for the design and production of bespoke footwear using computers. These techniques (already begun in the prosthetics industry) provide an opportunity to hoist surgical shoe making out of the last century into the front line of modern technology. With these techniques also comes an opportunity for centralised manufacture - with associated benefits to the cost and speed of production. The study was funded by the Department of Health and has shown the techniques to be feasible, but the dovartment has recently announced that funding for this 